\title{
MANAGEMENT OF JUXTA-ARTICULAR FRACTURES OF TIBIA MANAGED WITH HYBRID EXTERNAL FIXATOR
}

\author{
Murugasarathy Sambandam ${ }^{1}$, Duraisamy Ezhilmaran², Kalaiyarasan Thamizharasan 3 , Maharajothi Paramasivam ${ }^{4}$ \\ 1 Professor, Department of Orthopaedics, Chengalpattu Medical College Hospital. \\ ${ }^{2}$ Assistant Professor, Department of Orthopaedics, Chengalpattu Medical College Hospital. \\ ${ }^{3}$ Assistant Professor, Department of Orthopaedics, Chengalpattu Medical College Hospital. \\ ${ }^{4}$ Assistant Professor, Department of Orthopaedics, Chengalpattu Medical College Hospital.
}

ABSTRACT

\section{BACKGROUND}

Juxta-articular fractures of tibia are most serious and complicated injuries, which are found to be very difficult to fix and manage. These types of fractures usually occur due to RTA and fall from height; ultimately those fractures are considered as high velocity injuries, which is associated with extensive damage of soft tissue and vascular disturbances.

The aim of the study was to assess the functional outcome of juxta-articular fractures of the tibia using hybrid external fixator for closed and compound fractures.

\section{MATERIALS AND METHODS}

This is a prospective study carried out on 23 patients, who visited the emergency OP in Chengalpattu Medical College and Hospital, operated with hybrid external fixator for closed and compound fractures of juxta-articular fractures of tibia. All patients were assessed radiologically and clinically (union time, functional outcome) followed up sequentially.

\section{RESULTS}

The functional outcome and union of the proximal and distal juxta-articular fracture of the tibia was evaluated and operated with hybrid external fixator. The fracture of the proximal tibia united with an average of $14-18$ weeks (16.2 weeks). The fractures of distal tibia united with an average of 16 - 20 weeks (18.3 weeks) with minimal complications.

\section{CONCLUSION}

Hybrid external fixator systems are very useful in fixing the comminuted and compound juxta-articular fractures of the proximal and distal tibia. Hence, less invasive method of hybrid external fixator was tried which would minimise the complications, promote the fracture's further healing and stabilise the fracture, help early weight bearing and provide the full range of movement.

\section{KEYWORDS}

Distal Tibia, Hybrid External Fixator, Juxta-Articular, Metaphysis, Proximal Tibia.

HOW TO CITE THIS ARTICLE: Sambandam M, Ezhilmaran D, Thamizharasan K, et al. Management of juxta-articular fractures of tibia managed with hybrid external fixator. J. Evolution Med. Dent. Sci. 2017;6(51):3890-3894, DOI: 10.14260/Jemds/2017/841

\section{BACKGROUND}

Juxta-articular fractures of tibia are usually associated with severe soft tissue damage with or without compounding. The fracture that involve the proximal tibia affect the knee function and stability.[1,2] The distal tibia fracture also affect the ankle joint function and stability. The management of such high energy fracture became difficult for the orthopaedic surgeons. The goals of management of the juxtaarticular fractures are stable fixation of fragments; it will help to allow the joint movements. Injured soft tissue must be cared as well.

Proximal tibial fractures are complex injuries, difficult to treat as they are associated with dissociation of comminuted metaphysis from diaphysis and open wounds and extensive degloving injuries.[1],[3] Distal tibial fractures are associated

Financial or Other, Competing Interest: None.

Submission 16-03-2017, Peer Review 11-04-2017,

Acceptance 17-04-2017, Published 24-06-2017.

Corresponding Author:

Dr. Murugasarathy Sambandam,

Department of Orthopaedics,

Chengalpattu Medical College Hospital, Chengalpattu,

Kanchipuram District, Tamilnadu.

E-mail: s.murugasarathy@gmail.com

DOI: $10.14260 /$ jemds $/ 2017 / 841$ with fibula fracture, hence reduction is going to be difficult and fractures are almost compounding and comminuted.

For patient treated operatively, the residual disabilities are not only attributable to the severity of the injury but also to the complication and side effects of the operative intervention. ${ }^{[4]}$ Open fractures, fracture accompanying a compartment syndrome and fracture associated with vascular compromise usually require immediate intervention.[4],[5] The specific definition of hybrid external fixation is quite ambiguous. The term hybrid denotes no single or universally accepted treatment strategy/device. It is called hybrid fixation, because it combines wire fixation technique and pin fixation technique.[6] The tensioned wires provide improved fixation in the cancellous fragment, whereas the pin fixator give adequate stability to the diaphyseal fragments. [7]

Hybrid external fixator is simple and it is easy to apply; it can even be applied in emergency operation theatre; it is minimally invasive and also reduces the surgical time. It provides space for plastic and post-operative procedures. Hence, fracture can be realigned post-operatively as desired. Fracture reduction can be easily attained after frame assembly. ${ }^{[7],[8]}$ Hybrid external fixator provide rigid fixation; it allows immediate mobilisation of the joints and allow for early weight bearing.[7],[9] 
Hybrid external fixator technique minimise the osseous and soft tissue devascularisation and reduce the rate of complications that result from treatment modalities. In this study, we would like to assess the role of hybrid external fixator of juxta-articular fracture of proximal and distal tibia.

\section{MATERIALS AND METHODS}

The Juxta-articular fracture of the tibia were treated by hybrid external fixator system in a prospective study. A total of 23 cases were available for study with maximum followup of 2 years. All the cases are followed properly till the end of treatment. Among those 11 cases were proximal juxtaarticular fractures and 12 cases were distal juxta-articular fractures; 13 were compound fractures, in those 2 cases were Grade I compound, 5 were Grade II, Grade III-A were 4 cases, 2 were Grade III-B. Open fractures were classified according to the Gustilo-Anderson classification; 10 cases had association with fibula fractures.

Most of the injury was sustained by road traffic accident and few of the cases by falls from height. Those are all high velocity injuries; age group of the study was between 20 - 65 years, Males 15, Females 8.

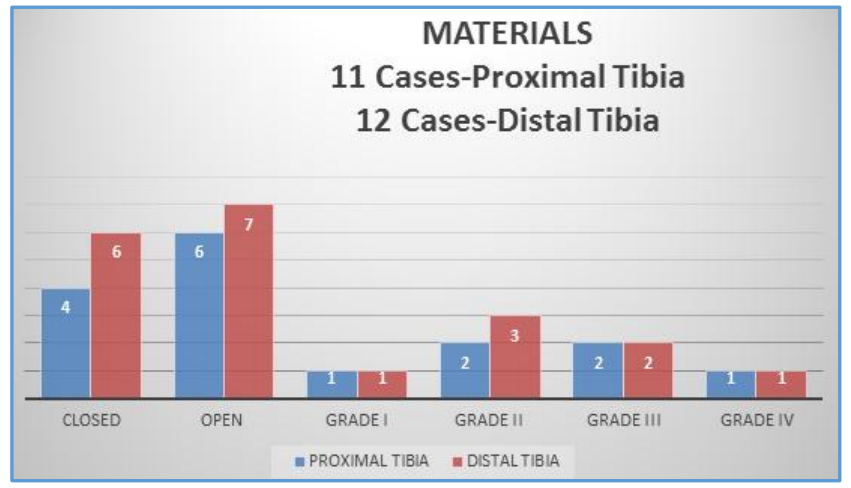

Diagram 1. Illustrated Diagram shows the Various Cases

\section{Post-Op Protocol}

Ankle and knee mobilisation was initiated within a day, pin care site was advised and partial weight bearing was allowed with walker on day two. Intravenous antibiotics was given for 2 days in closed fracture, 1 week for open fracture and then oral antibiotics was given for a week.

\section{RESULTS}

The functional outcome and union of the proximal and distal juxta-articular fracture of the tibia was evaluated and operated with hybrid external fixator. The fracture of the proximal tibia united with an average of $14-18$ weeks $(16.2$ weeks), the fractures of distal tibia united with an average of 16 - 20 weeks (18.3 weeks) with minimal complications.

We followed IOWA Scoring System to assess the functional outcome of the proximal and distal juxta-articular fractures of the tibia, which was treated with hybrid external fixator. Out of 23 cases in our study we had excellent results in 10 cases, good results in 7 cases, fair in 4 cases, poor in 2 cases and results are shown in diagram.

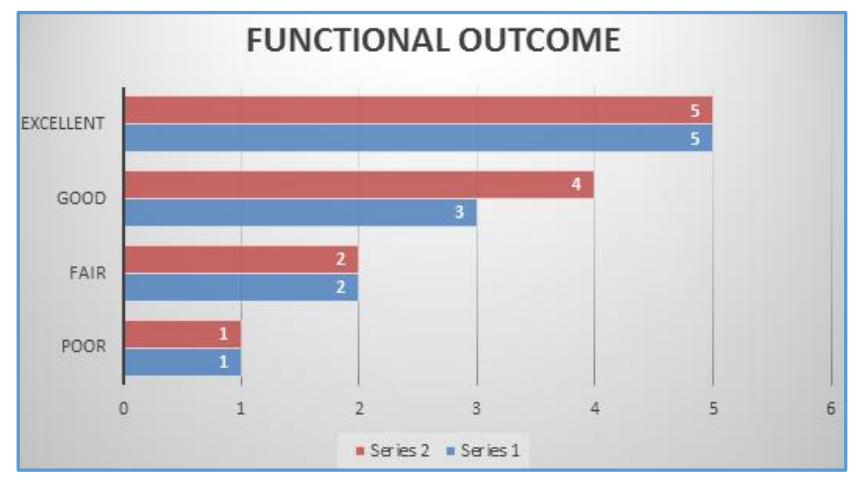

\section{Diagram 2. Illustrated Diagram shows Outcome of the Patient}

\section{Complication}

We had superficial pin tract infection in 3 cases, which was treated with IV and oral antibiotics for a week and daily dressing was made; ankle and knee stiffness in 3 cases which was overcome by aggressive physiotherapy. Out of 15 cases we had major complication in 3 cases, severe infection in one case which was debrided and wire was replaced. One Equines was corrected by Ilizarov ring fixator, one delayed union with angulation was corrected by Ilizarov ring fixator and one delayed union case was bone grafted as well.

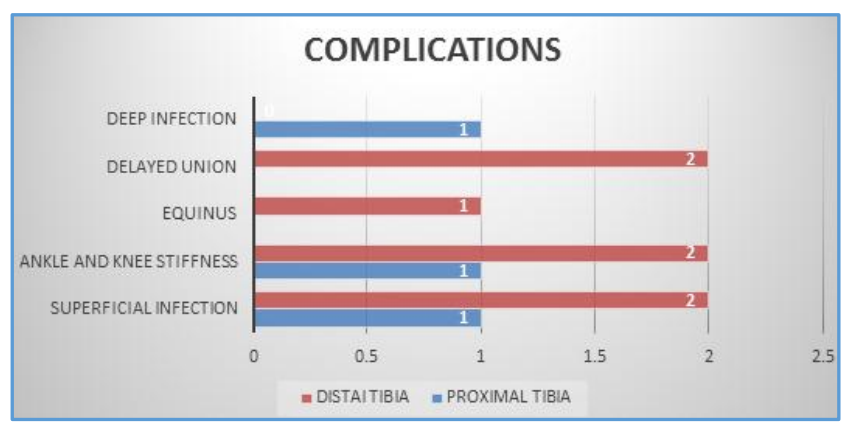

In proximal tibia fracture, median and interquartile range time for fracture union is 16 weeks and 2 respectively. Also for distal tibia fracture, median and interquartile range time for fracture union is 18 weeks and 1 respectively.

\section{Followup}

All the patients were periodically followed up for weekly once for first one month, then monthly once until fixator and cast was removed. Proximal juxta-articular fracture healing occurred in 14 to 18 weeks (Avg. 16.2 weeks). Distal juxtaarticular fracture healing occurred in 16 to 20 weeks (Avg. 18.3 weeks). Union was confirmed by taking Radiograph of anterior-posterior view, lateral views and clinically. Once union was confirmed, dynamisation was done and kept in dynamisation for a month; after a month of dynamisation fixator was removed. Protective cast was applied to protect the union for a month, then cast was removed completely and allowed for full weight bearing without any support. 
Illustrations

20/M, Grade II Compound Distal Tibia Fracture, Left

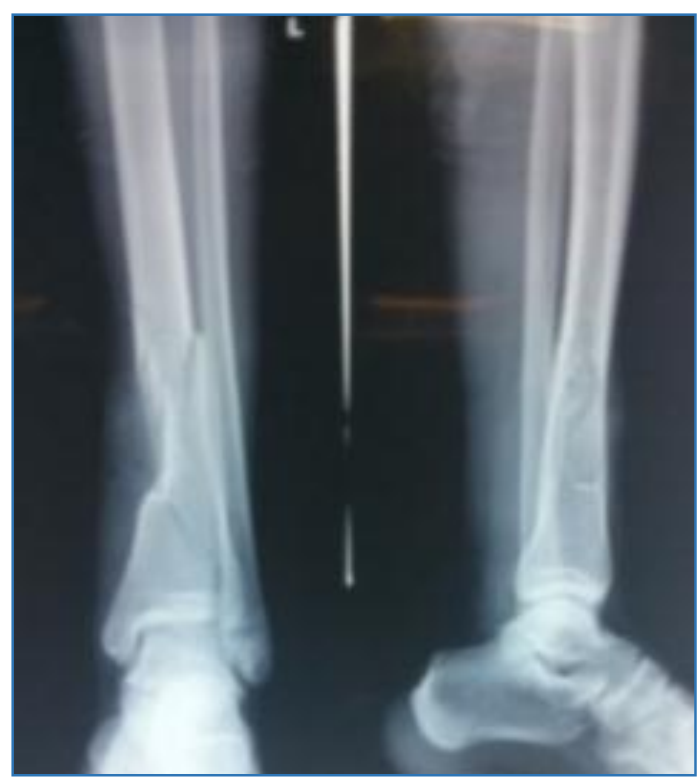

Figure 1. Pre-Op

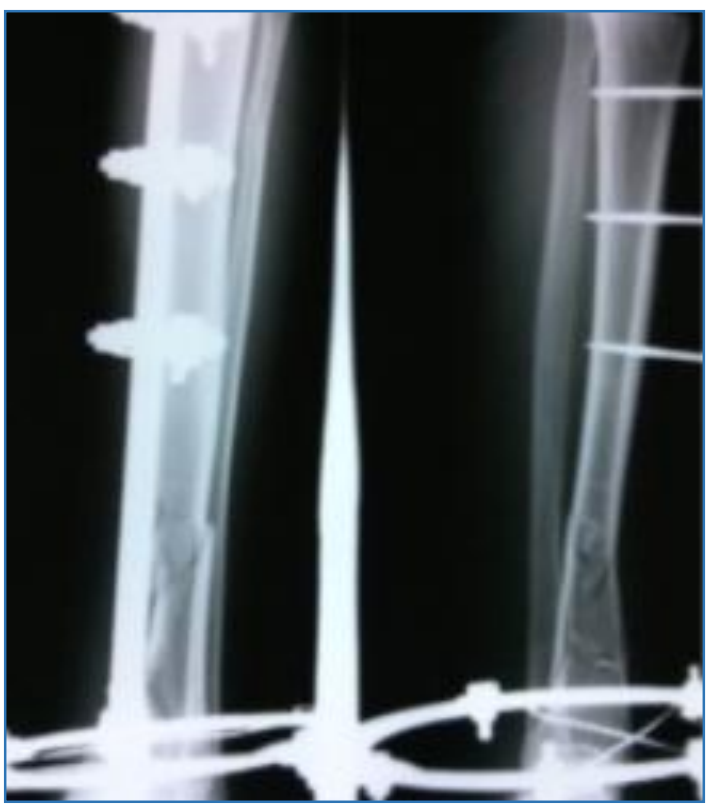

Figure 2. Post-Op

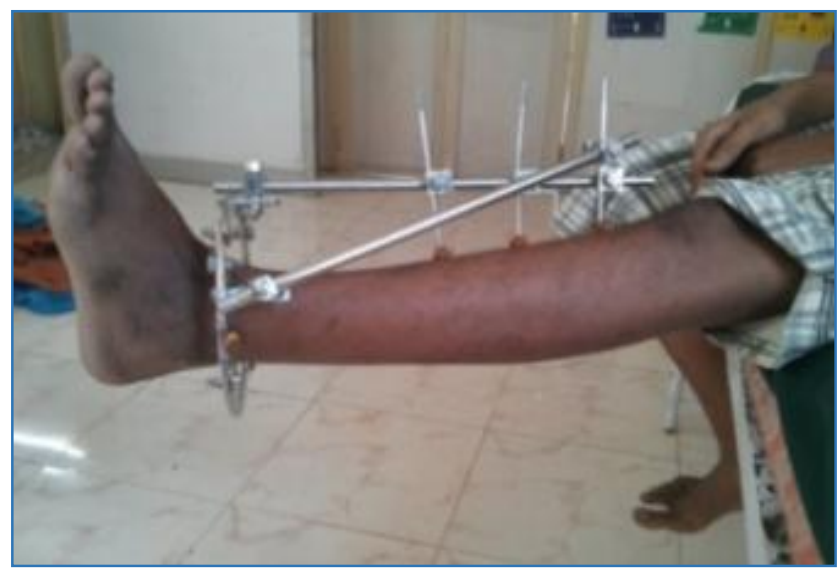

Figure 3. Full Knee Extension

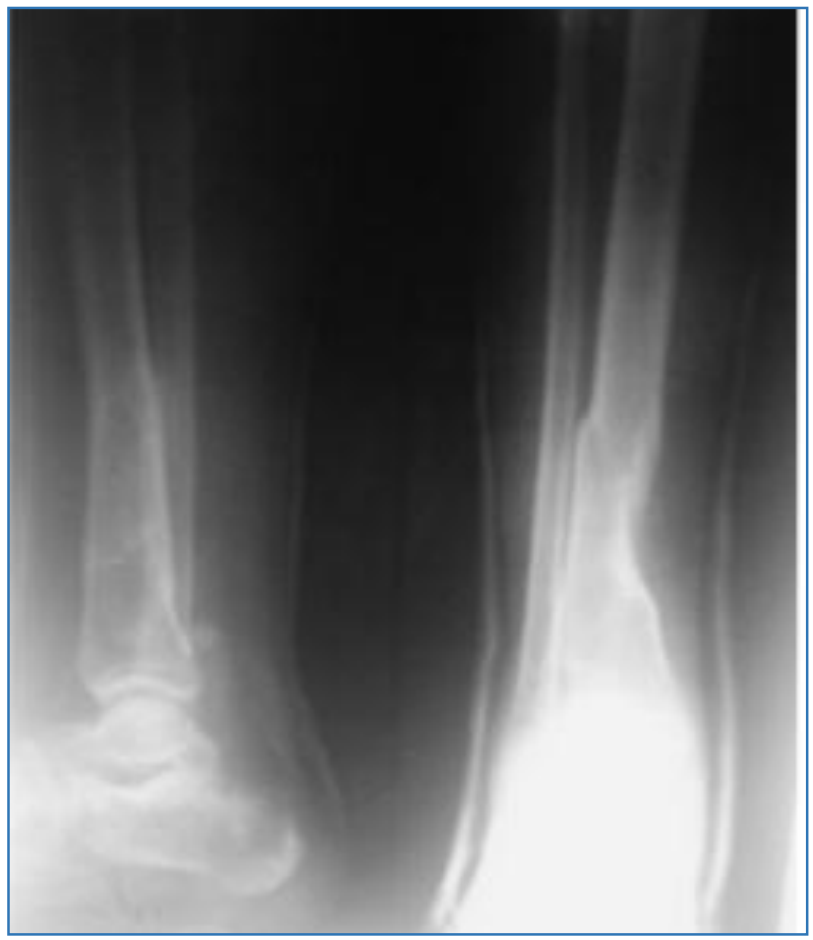

Figure 4. Six Months Followup

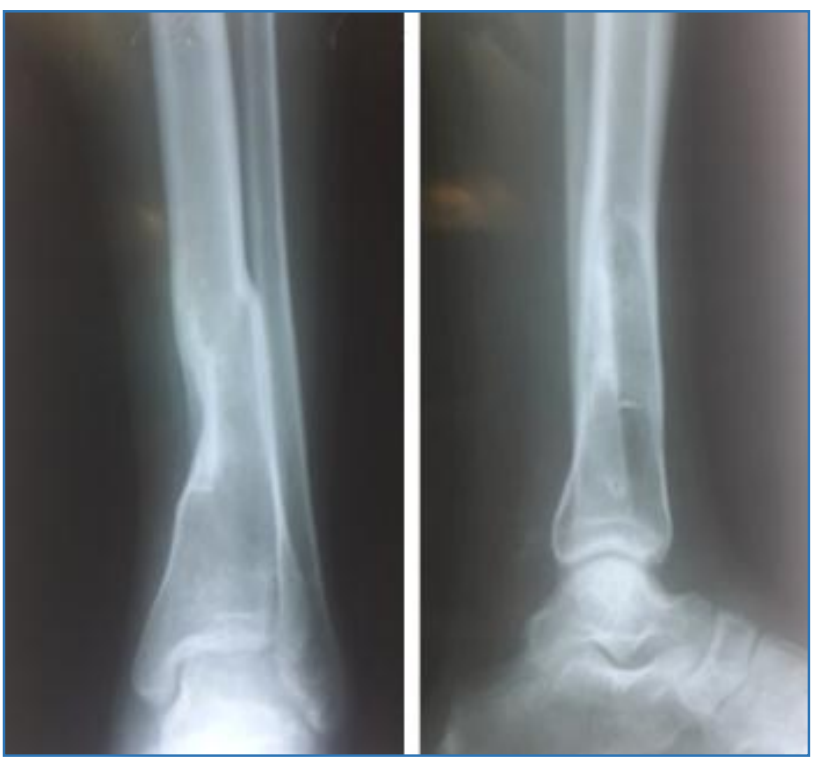

Figure 5. Two Years Followup

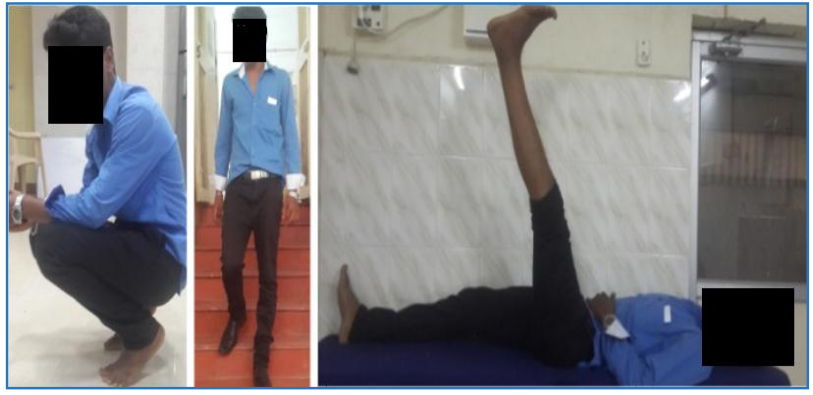

Figure 6. Clinical Demonstration after Two Years 35/M, Grade III A Fracture BB Left Leg Proximal Third 


\section{Followup}

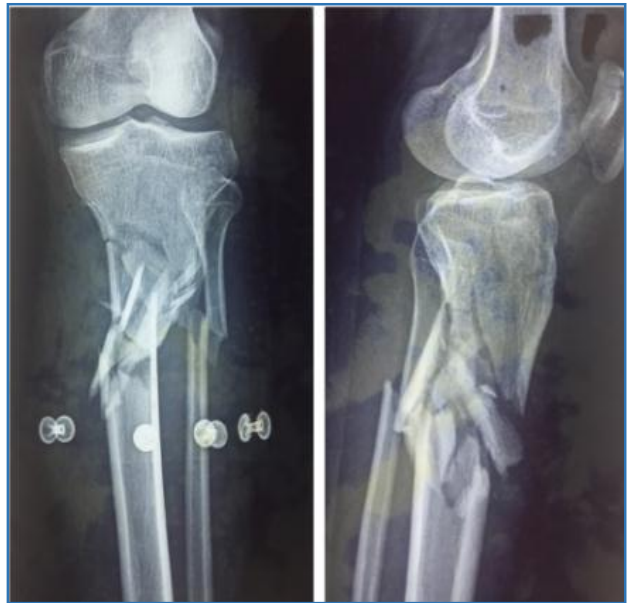

Figure 7. Pre-Op

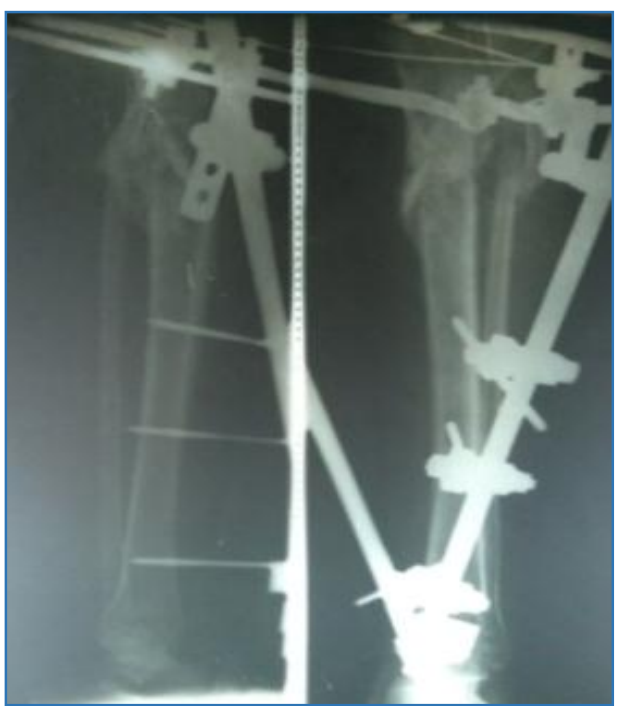

Figure 8. Post-Op

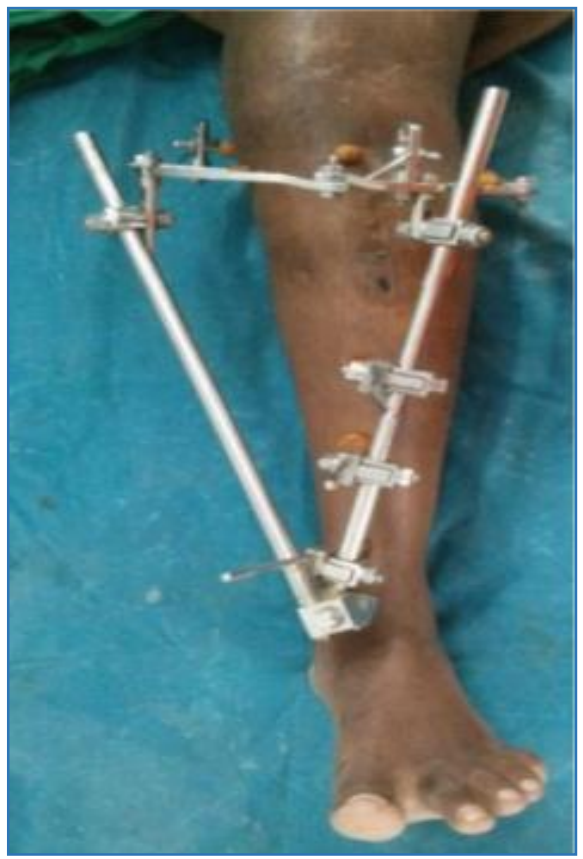

Figure 9. Clinical

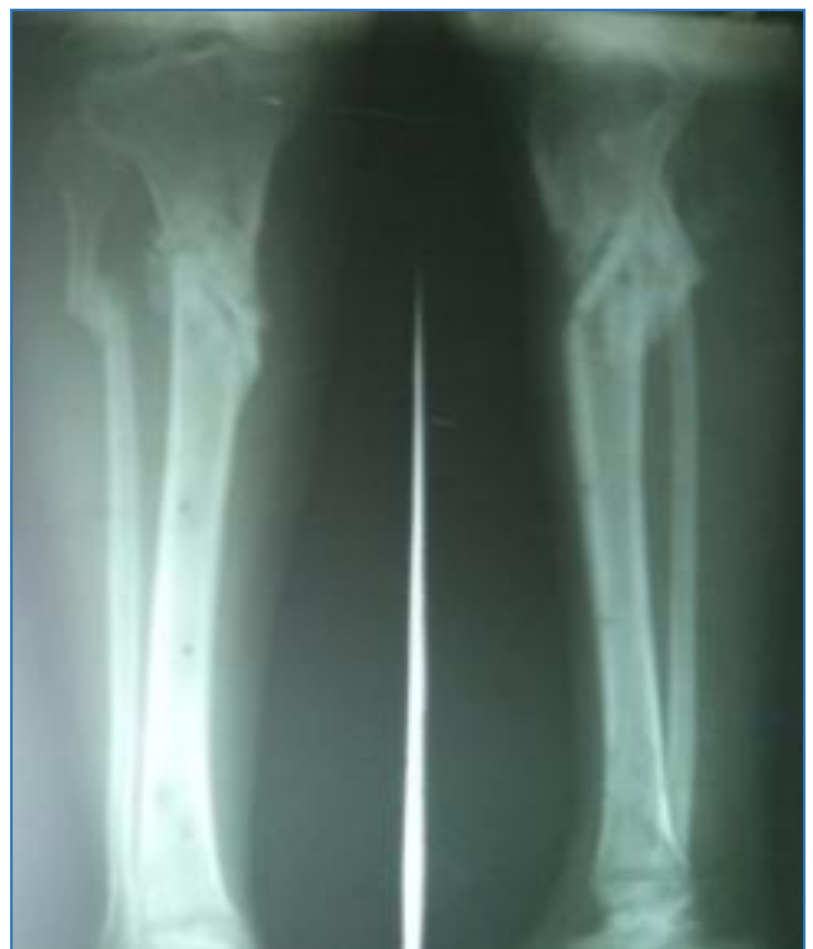

Figure 10. Six Months Followup

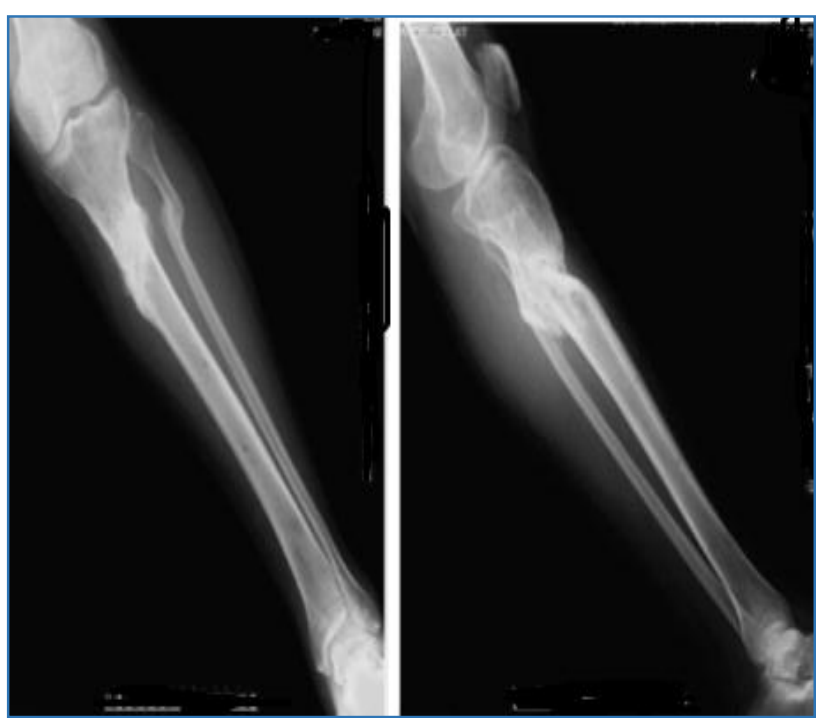

Figure 11. Two Years Followup

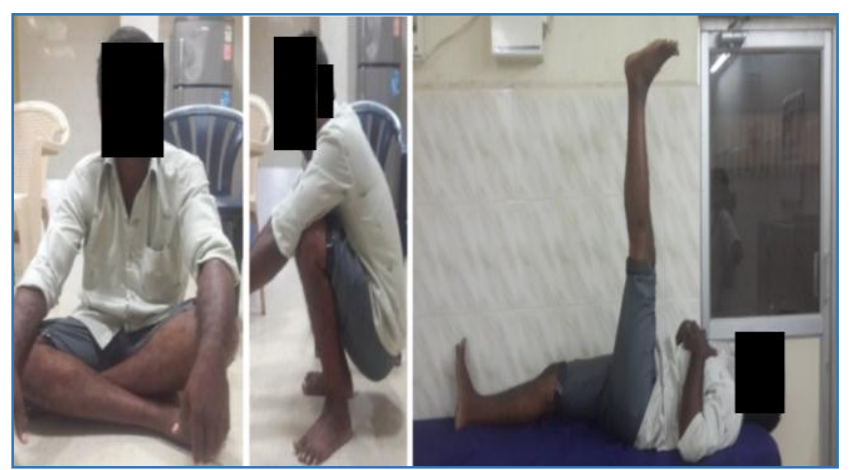

Figure 12. Clinical Demonstration after Removal 


\section{DISCUSSION}

The Juxta-articular fractures of tibia usually fall in metaphyseal region. Among the fracture, it is also difficult to treat effectively. Before considering the fixation, soft tissue status, severity of injury, degree of comminution and involvement of articular damage should be considered. The goals of treatment were-

1. Anatomical or near anatomical reconstruction of proximal tibia or distal tibia.

2. Restore the alignment of limb.

3. To fix and stabilise the Metaphyseal-Diaphyseal comminution.

4. Early knee and ankle mobilisation.

5. Early weight bearing.

6. To allow biological union of the fracture, all these can be achieved by hybrid external fixator.

All these things were achieved with hybrid fixator.[10] Various modalities of fixation are present like Casting, Plating, External fixator, Locking plate, Ilizarov fixator all have good fracture union results. But they do not address all of its problems. This should be accomplished using techniques that minimise osseous and soft tissue devascularisation in the hopes of decreasing the complications resulting from treatment. The present study was undertaken to determine the efficacy of the hybrid external fixator in treatment of the fractures of the tibial juxta-articular region. Severe comminution, open injuries which becomes difficult to be managed by open reduction and internal fixation, this is a simple and user-friendly technique. This frame fixation does not require meticulous preoperative work like that required in Ilizarov technique.[10],[11],[12],[13] The biological healing of the fracture is promoted without disturbing the haematoma and soft tissue which surrounded the fracture. Hence, fracture reduction was done with closed manner by which already compromised soft tissue will be protected from further damage and prevented from Skin necrosis, Bone necrosis and Non-union which result in less morbidity. It is a good technique for fixing comminuted proximal and distal third of tibia fractures.

\section{CONCLUSION}

Hybrid external fixator systems are very useful in fixing the comminuted and compound juxta-articular fractures of the proximal and distal tibia. Hence, less invasive method of hybrid external fixator was tried, which would minimise the complications, promote the fracture's further healing and stabilise the fracture, help early weight bearing and provide the full range of movement.

\section{REFERENCES}

[1] Thakur A, Salaria A. Evaluation of role of hybrid external fixator in complex proximal tibial fractures. A review of thirty five cases. IOSR J Dental and Medical Science 2015;14(4):93-7.

[2] Hol M. Tibial condyle fracture. J Bone \& Joint Surg Am 1967;49(7):1455-67.

[3] Schatzker J, Tile M. Fractures of the tibial plateau. The rationale of operative orthopaedic care. New York: Springer-Verlag 1988;279-95.

[4] Ramesh R, Ajeet H, Dayanad K, et al. Clinical follow up study on the management of complex Metaphyseal fracture of the tibia with hybrid exfix. 2016;8:15090-4.

[5] Sirkin MS, Bono CM, Reilly MC, et al. Percutaneous methods of tibial plateau fixation. Clinical Ortho and Related Research 2000;375:60-8.

[6] Arivazhagan ES. Functional outcome of various modalities of management of distal tibial fractures. 2016;15(8):12-9.

[7] Gupta SKV, Sunil G. Management of tibial metaphyseal fractures by hybrid external fixator. Open Journal of Ortho 2014;4:84-9.

[8] Yang L, Saleeh M, Nayagam S. The effect of different wire and screw combinations on the stiffness of hybrid external fixator. Proc Inst Mech Eng $\mathrm{H}$ 2000;214(6): 669-76.

[9] Mallik AR, Covall DJ, Whitelaw GP. Internal versus external fixation of bicondylar tibial plateau fractures. Orthopaedic Reviews 1992;21(12):1433-6.

[10] Gandhi D, Mulay S, Chaudhari T, et al. Hybrid fixator fixation modality in compound communited fractures of tibia. Int J Res Health Sci 2015;4(4):807-10.

[11] El Barbary H, Ghani AH, Misbah H, et al. Complex tibial plateau fractures treated with Ilizarov external fixater with or without minial internal fixation. Int Orthop 2005;29(3):182-5.

[12] Kataris H, Sharma N, Kanojia RK. Small wire external fixtion for high energy tibial plateau fractures. J Orthop Surg 2007;15(2):137-43.

[13] Chapman WM. Chapman orthopedic surgery. Management of fractures, non-union and mal-union with Ilizarov technique. $3^{\text {rd }}$ edn. Philadelphia, PA: Lippincott William and Wilkins 2001:1082-9. 